\title{
How the Korean Soap Opera Influence Sri lankan's Life
}

\author{
Shyama Jinasena \\ University of Colombo, Sri Lanka \\ *Corresponding Author: Shyamajinasena82@gmail.com
}

Copyright (C 2014 Horizon Research Publishing All rights reserved.

\begin{abstract}
This research paper determines how, the South Korean soap opera influence sri lankan's life style. In 2012, Sri lanka Rupavahini cooperation introduced Korean soap opera to the Sri lankan home audience. That selected opera is famous in Korean \& worldwide audience. It contains the Korean culture, religion, myths \& also the Korean society. In the beginning of this Korean drama series Sri lankan audience was not allowed to observe this opera. Because of the culture, such as language and the era were the reasons it. Sri Lankan audience watched this drama for the first time as a result of their habit of time schedule. To prepare research findings the methodologies used were interviews and questionnaires. In addition attending as a research partner in the sri lankan civil society. How simple television production can be used as $\mathrm{s}$ tool for effective social changes $\&$ win millions of hearts and minds in the region was researched. Most writers wrote about that series \& published newspaper articles and books about the theme of this story. Sri Lankans imitate Korean drama characters by their clothes, culture, walk, religion etc. As a result of the addicted audience Sri lankan market too blindly focused in this process. They introduced hairclip, dresses, shoes, makeup items \& accessories. Influences of this drama created a big market potential among the lankan civil society. Likewise tuition masters, businessmen followed using the picture of female characters for their publicity. The hidden truth behind it is that they used the ideology of this soap opera for establishing in the Sri lankan civil society. Korean soap opera had changed the Sri lankan life by the successful characters and ideology.
\end{abstract}

Keywords Soap opera, Culture, Audience, Era, Ideology

\section{Introduction}

There was a Korean soap opera, which was dubbed in Sri lanka called "Sujatha diyani or Changumi", but it's real global name is "Jewel in the palace" it became the most famous in Sri lanka. In the beginning of this soap opera Sri Lankans did not much demonstrate their dramatic theme, story and clothing styles. Sri lankan audience cared only about emphasizing on the telecasting prime time of "Oshin". As a result of this the audience changed their focus to in Changumi. However finally Sri lankan television viewers ended up watching soap opera. That tele-drama selected by Rupavahini Corporation became the newest Korean experience to the Sri lankan audience. So Sri lanka settled with this type of tele -drama day by day. However Sri lankan audience attracted by this live characters, soap operas and fictional stories, Following these mentioned items the Sri lankan audience followed suit.

The theme of it was historical. It was about the Korean imperial's period going back to ancient history. About 500 years ago during the time of Chosun Dynasty, Korea boasted a rigidly hierarchical and male dominated social structure. Set in this period, "Jewel in the Palace" is based on a true story. This dramatic story comprises of the royal kingdom of King Jung Jogn who lived in Korea and highlights his palace administrative systems. To achieve this dramatic story for the audience heart director of this soap opera used many female characters. This soap opera describes how they carried out living in the king's palace.It always described about the most valuable customs in this palace. The whole story was based on the values, myths and observations.

Never-the-less, in this drama the target group were women and children. Sri lankan women were easily attracted by this soap opera because of its lovely attractive characters of this fictional story. Specially, Changumi is the most popular and effective character in this soap opera. Changumi' character landed herself as a royal cook, later becoming the royal physician, then ultimately the physician in charge of the king. Other characters of this historic theme story such as king and queen, choi, han, min and all the supporting characters too helped to develop the story as the most successful one. Especially the story of this soap opera flows by the most popular character "changumi" whose famous actress is called "Lee Young Ae" has a most suitable face for this dramatic soap opera. Her character describes all the things that had to be included for women. At the middle of this soap opera Changumi joined with sir Min, who works in the kingdom military and it grows as a respectable love story between both of them. So that too helped to keep in Sri lankan audience the following day episodes to watch. Soap opera is the most attractive one for all world audience, because of its theme contains full of love, fear and all 
emotional movements. So that's why people allowed staying connected with such soap operas in the world. All the characters who act in the soap operas determine what the realities of the world as a story.

This soap opera gives some ideology impacts to our sri lankan audience because in this story it describes how people rise up from the boundary level. Main character of this drama Changumi gives big potential spot light to the sri lanka society, specially for women to achieve their targets with the difficulties of their family, society or any other weakness coming from their lives. So, all the characters help to build up the main character with the more successful ideologies from their characters. It helps to make a most suitable dramatic story as a magnet to capture the audience.

A group of Sri lankans at the on-set joined with this drama but eventually the entire sri lankan society was attracted by this drama's dramatic story, live characters and all successful. Jewel in the palace was named "Sujatha diyani" by the Sri lankans, if it is not related to it's theme, custom or period does not match with the Sri lankan style. Most of Sri Lankans embraced soap opera as their life partner.

\section{What is Soap Opera?}

The soap opera began in the early 1930s with 15 -minute daytime radio episodes and was inherited by television in the early 1950s and expanded to 30 minutes. By the mid-1950s soap operas dominated late morning and early afternoon weekday television programming as they had dominated a similar time frame in radio programming during the previous decade.

Soap opera is a story about the people's burning problems that took place \& going to take place seen and heard by others. In the social life also people like to make use of someone's problem and enjoy with each others. As a human, it is a normal habit of the people. Because as a humans, people always try to search other's garbage and almost try to share with others. So as an impact of human life, people will explore others problems and always try to make up stories about ongoing situations. Soap opera also the thing that basically aims human likes and dislikes keep in dramatic representation of their own lives and concerns. It is also a dramatic view of the people behavior.

Soap opera is an ongoing work of fiction and episode in nature.They are stories told over extended periods with different characters being at different times. Even most of the story lines are rare and affects several characters and possibly inter connects with others stories. Soap operas tend to focus their plots and storylines around family life,personal, sexual relationship emotional and moral conflicts. So it became as a fictional dramatic view in soap opera. While many of these scenarios might show up in other programs soap operas are filmed to reveal the day to day lives of its characters building in the story. A crucial element that defines soap opera is the open-ended nature of the narrative, with stories spanning several episodes. The defining feature that makes a program a soap opera, according to Albert Moran, is "that form of television that works with a continuous open narrative. Each episode ends with a promise that the storyline is to be continued in another episode".

A crucial element that defines soap opera is the open-ended nature of the narrative, with stories spanning several episodes. The defining feature that makes a program a soap opera, according to Albert Moran, is "that form of television that works with a continuous open narrative. Each episode ends with a promise that the storyline is to be continued in another episode."

According to Wright Mills View (1916-62), "Commercial jazz, soap opera, pulp fiction, comic strips, the movies set the images, mannerisms, standards, and aims of the urban masses. In one way or another, everyone is equal before these cultural machines; like technology itself, the mass media are nearly universal in their incidence and appeal. They are a kind of common denominator, a kind of scheme for pre-scheduled, mass emotions."

Soap opera is a serial drama on tv or radio story lines dealing with the lives of multiple characters. Soap opera includes multiple characters with the sequence story series ,passing episodes ,nature and narrative. Most of soap operas run away with emotional relationship. Soap opera contains emphasis of family lives, personal relationship, and sex emotional and always covers tropical issues.

An especially soap opera determine a story and contains many behaviors of lives. It was always reality and that's why audience almost loves and get addicted to soap operas easily after becoming a lunacy to soap opera tele series. The addicted audience can't miss even one episode also. So that's why they check from everywhere whether they missed any episode story and if not they will find out details of the missing story that they missed earlier.

Luciano Berio (1925) Cited, "Opera once was an important social instrument" According to his views enjoy learning about complex relationship between different characters and watching them develop over time from the soap opera. Audience will think about the characteristic relationships among the soap opera. After thinking about the connections between the characters, they thought about what situations had influenced to develop the characters. So finally they talk with each other about the soap opera story characters and situations of the dramatic basic. It may spread like exploration in the society system. People make a discussion about the dramatic soap opera episodes and movements, whether is it true or not???

Soap opera quoted by Jesse Leonardo (2005) "Any pathetic, fantasy, unreal drama shown on basic cable daytime hour on television." It is like a narrative puzzle, such as opportunities to guess what is going to happen next, in the fictional drama. Audience is always alerted to know what is going to happen in the next incident. It will generate large number of audience for the soap opera.

In the society soap opera has huge audience for making the social revolution. It gained in talking about soap opera with other fans reading the magazines, newspaper articles and 
books to get numerical data chatting with each others about the soap opera. The society criticizes soap opera making a huge campaign in the society for making a new revolution about the soap opera ingredients.

Soap opera almost performs with the same set of costumes. All the characters help to grow a fictional drama and characters develop with the similarities in the soap opera. The opera performed every night, was full of entrainment, sweet and most delightful. Some of the songs seemed to melt my very soul." by Francis Burney (1752-1840) according to his view same set backgrounds can be used to shoot the whole soap opera. Sometimes it may be very little location for filmmaking the soap opera.

However soap opera is a fictional drama, which indicates attractive story perform at the suitable platform. It was a huge campaign to gain people to make a social revolution about somewhat theoretical background. So finally soap opera can easily catch the audience from its fictional and dramatic story.

\section{Rationale}

After the John logie baeard, investigated the television system to the world. Whole the world change by the new technology day by day. World connected with the television system for more reasons. But in now a days tv system keep in peak of the mountain after the attacked to the all ways for whole world society and Sri lankan society also. Some attraction from the television system and in these days it kept in silent way. However in Sri lanka audience has more experience about the translated foreign soap opera like Oshin, Robinzo crooso, Ocean girl and such as bollywood soap opera named Praveena, Mahagedara and near future there was more effective Korean soap opera telecasted on Sri lankan rupavahini called full house. But most of foreign soap operas created big argument in the society. But these Korean soap operas with the changumi also no more social comments or arguments from the Sri lankan society. Audience strongly embracing it talc story and there was a changumi lunacy in that telecasted period.

However this jewel in the palace story telecasted in several countries in the world before telecasted it in Sri lanka. Every countries had been made more effective things all around the world by the ideology of this drama. So as a result of winning ideology and the dramatic story Sri lankan audience also had more influence by the changumi soap opera. According to Sri lanka Rupavahini data sources, there was a highest ratings showing in Sri lankan daubing history. Finally it may be a reason to change the Sri lankan society system to collapse more things. So that's why rise up more researchers for about that.

Sujatha diyani has was a more influence able dramatic story and more effectiveness characters also. It was a most reasonable thing for rise up more influences for the Sri lankan society. In that case research pointed out what are the influences for the society in Sri lanka from this soap opera. It was more researchable and there is more effectiveness about the South Korean society system substitute for the Sri lankan society also. In this period of this fantastic soap operas theme in the Korean soap opera not related for the sri lankan systems but it also embracing by the Sri lankan audience as their reasonable relationship. However, had been made influence as far as whole Sri lankan society by the ideology and successful characters may be researchable.

\section{Story in Deep}

Jewel in the palace is a historical fictional soap opera that happened real story in South Korea about 500 years ago during the time of Chosun Dynasty, Korea boasted a rigidly hierarchical and male dominated social structure. Set in this period, "Jewel in the Palace" is based on a true story about a legendary girl. This story produced by the Munhwa Broadcasting Corporation and it directed by Lee Byung-Hun in 2003. This soap opera earned highest viewing rates in the podcasted period in the Korea and after that it telecasted more than 50 countries in the world.

This story was about really happened incident in the cooking section in the king's palace. Queen's murder case was the main incident and whole drama surrounded that case. Changumi was an orphaned girl because of her mother and father destroyed by the cruelty of palace ruled system. But that daughter also had to work at the palace as a cooking member at the kitchen. When story flows through the scene by scene, it learned the secrets of South Korean cooking methods. In this soap opera main character of Changumi presents many roles such as lady, cook, herbalist, slave, researcher, detective and conspirator. In her memorable life teaches lots of things to whole society how rise up from the endeavor. All the episodes created as a fictional about murder case that happened in the palace. Changumi was the investigator of that mystery. All the characters also support to develop the main character of this fictional opera.

This orphaned girl 15th century Korea who raise from her servant class beginnings to become the first women physician to the king. In the childhood of Changumi, had lost her mother and father also. But her mother taught write and read language very well. So Changumi sets her sights on the long range goal of entering the royal palace and becoming the highest kitchen lady, her only goal was an injustice committed against her mother that written down in the official log book. When her mother had been kitchen lady, Changumi works tenaciously to learn everything. She can and perfects her skills. It makes game among the Choi's family. Choi family had always against with the Changumi. As a result of choi family ceateral conflict between Changumi for treason who made by Choi family always try to get in the trouble to Changumi. Not only for the Chagumi but her mentor also made trouble in series. All passed episodes their roles included with supreme responsibility to prepare delicious beautiful and healthy foods.

As a result of this happened chain of incident Changumi is 
framed for high treason, demoted to a slave and exiled to a remote island. But Changumi still has a goal to achieve. Then she change her character as a physician lady according to facility that provided by the slave island. She begins studying and training in the field of medicine. Amid the dramatic events a beautiful and moving love story develops between Changumi and military officer sir Min. We can see this love story grows with the as he admires her intelligence courage and tenacity.

\section{Methodology}

To examine the impact of the soap opera for the Sri lankan audience by using mixed methodology of qualitative and quantitative. For a quantitative methods used questionnaires for gathering data from the Sri lankan audience for measure, how influence had been made by the Korean soap opera of Sujatha diyani.

In Sri lankan according to the department of census and population data there is near two lakz of population. They are multinational, multi religion and multi collective of people who lives in Sri lanka. Among that whole population of 13.6 million of people became television audience in Sri lanaka television networks. I selected 100 people causally as my sample for the research to collect data. As a sample of my research without age limit of people and without consider about their sex, religion, national statement or living place even didn't consider for that selection of the research. Primary sources were questionnaire to collect the data. In this research used 100 various kinds of people perchance method from all around the country to gather data.

In this research to determine how to make a influence for the Sri lankan audience by the Sujatha diyani of Korean soap opera. For that used several primary data collection methods to collect data for developing the research. As these research data collection resources it used several primary data collection methods to gather data for developing the research. Specially, various types of people used for an interview to collect the data for analysis and get conclusions.

Observation also used to gather data for this research as primary data collection methods. In depth observation about the soap opera of Changumi and relevant Sri lankan society as a member of the society also observed by the research. As secondary data resources it used newspaper articles, books, journals, social networks and web sites also used for gathering data.

\section{Results}

After gathered data from using data gathering tools in Sri lankan audience about the soap opera of "Sujatha diyani" had more influenced by the many views of the Sri lanka. It sometimes sociological way and sometimes ideological and philosophically change had been established in the Sri lankan society.

According to this dramatic theme era was not related to the
Sri lankan society. Because it was an empirical era story and Korean society also changed than that story basically cited era. In this drama's main set or background is a king's palace. All the incidents happened in the king's palace and it described how the empirical systems controlled under the ruled.

This soap opera costumes also not related to us. Because of these costumes are traditional dresses in the Korea. Their culture also not same to us and only same thing is they has myths like Sri lankan. But their myths also different than our sri lankan myths. Their traditional ways almost help to keep in thought our Sri lankan's also return to their ways.

However as an impact of this dramatic soap opera most of Sri lankan audience also grasping that topic as their most famous and most viewed time one. As a result of the most popular soap opera it influenced to the Sri lanka families. Because Sri lankan house wives had attended with this soap opera from 6.30 without consider about their families. So husbands and children had to wait until mother comes after watched Changumi. But as an impact of the Changumi there are more effectiveness had occurred for the Sri lankan life styles.

Specially according to the observation results urban areas of Sri lanka most affected by this soap opera. After got more data from the observation, it made to prove that answer given by who participant for the survey. Suburb areas affected from this soap opera more than urban areas of the country. Especially all the women who live in those main areas of the country made more affected by the drama. According to observation results plantation sector also had affected by soap opera to change their living styles. But women and school children had been most affected by the soap opera series in main areas in Sri lanka.

This soap opera had made the more influence for the women, girls and school children than boys. From the observation results big amount of school children and specially girls and women had been influenced by the Sujatha diyani soap opera. Men and boys also influenced by somehow, but amount wasn't bigger than girls and women. After telecasted Changumi Sri lankan girls part always going to imitate as Changumi character and ideology.

This survey keen in "why actually Sri lankan audience make big attention for that series?" So got data from the questionnaire it's indicated what is the reality.

Table 1. Why people like this soap opera?

\begin{tabular}{|c|c|}
\hline Reasons & Percentage \\
\hline It's characters & $32.3 \%$ \\
\hline It's Ideology & $17.1 \%$ \\
\hline Dramatic episodes & $35.6 \%$ \\
\hline Social society influenced & $15 \%$ \\
\hline
\end{tabular}

This table presentenced what were the really made a social influence among the Sri lankan audience. Big amount of 
dramatic episodes indicated the reason for made such influence had made among the society. Its characters also help to grow some influence among the audience.

This drama effected for the Sri Lankan fashion industry also. Especially Sri lankan women had been embracing most of Korean patterns from this soap opera. After the telecasted this opera according to this research observation and after supplied collected data, there was high percentage of averages indicate there was some society changes had been occurred from the opera. Korean cloths designs, hair styles, bags and number of Korean styles added to the Sri lankan fashion industry. After surveyed from the questionnaire data collected how to influence this Korean soap opera among the Sri Lankan fashion industry. This table indicate how had been made soap opera made some influence for the Sri Lankan fashion industry.

Table 2. What are the influences of this soap opera?

\begin{tabular}{|c|c|}
\hline Fashions & Percentage \\
\hline Cloths & $14.6 \%$ \\
\hline Hair styles & $56.7 \%$ \\
\hline Bags & $8.5 \%$ \\
\hline Accessories & 20.2 \\
\hline
\end{tabular}

This table indicates how women alert with the Korean fashions. Especially women have got hair styles from this drama and actually they used Korean type hair clips to decorate their hair. In these days most of women use such as hair clips in that situation. Businessmen who has stoles such accessories had big business from that hair clips. Sri lankan also seemed like Korea and most of women used such hair dresses. Not only hair clips Sri lankan women used hand bags and shoes but also like Changumi and impact of the Changumi story.

After telecast these soap opera series it extremely impacted for the Sri lankan media industry also. Because in these days no more very famous drama. In that telecasting time in the Sri lankan television channels and lots of people alert with the soap opera and made big discussion in the society. That's why most of people alert with this drama and as a experimental first time lots of people join with this drama and but after the impact of this drama most of Sri Lankans were addicted with this drama.

Most of day cards issued with the Changumi's face and other famous characters of this drama such as solider Min, King \& white characters of this drama like supervisor women Han in the kitchen had been used to color the day cards. Most of school little ones and lunacy bought dozen of such day cards. Not only for the day cards they used Changumi's face to make publicity in posters of tuition classes and political campaigns and when established more social works in Sri lanka imagine makers in Sri lanka imagine makers used changumi's face for their posters. Because of Changumi was the most famous character in the society than Sri lankan characters and specially people address about the ideology of Changumi in the social, religion and political campaign to describe the power of women.

However impact of this drama Sri lankan media market had more duplicate CDs also. These all CDs about Changumi story who got the Changumi television series from the internet and published as a CD to the audience. So however advertisements that published on the $\mathrm{tv}$, radio and newspapers also used Changumi's image as their advertisement terms.

\section{Conclusions}

After the telecast Sujatha diyani tv series Sri lankan society had been change by the influence of this series. According to the research results it $45 \%$ of Sri lankan people watched that soap opera series continuously without missed any episode. If missed some episode they watched it however from internet or something else. So as a result of this soap opera Sri lankan whole society had changed. It was social, political, economy, religion and all the section such as health, agriculture also changed according to the influence of this drama.

Most of Sri lanka television industry had been changed. For an example television producers want to change their day schedule times. They want to make most effective charactors such as Changumi. For an example one of drama made named "Sujatha puthra" such like theme of this Changumi story. However in the whole mass media industry Changumi became a heroic character in the Sri lankan society. So media also must create such character as a influence and successfulness of this characters.

After telecasted this drama Sri lankan living society has been changed. Specially women changed and always try to become character like Changumi. Then try to learn how to cook like Changumi and how to give medicine like Changumi. Sri lankan women changed their speaking ways also like Changumi. Sri lankan babies also named like Korean names in that telecasted time period. As an influenced of this soap opera Sri lankan home styles also changed. Main thing is people loved to use Changumi image as their daily schedules. So that's why most of Sri Lankans almost used Changumi styles for their daily use. For an example they used hair clips such like Changumi.

According to social changed economic sector also influenced by the Changumi tele series. Because market wants to supply what are the social needs. So, industrial market also wants to set with the social needs. As influenced of this drama there were lots of things come to the market such as day cards, calendars, T-shirts, hand bags with face of Changumi.

However market made a lunacy about the changumi for the Sri lankan consumers. So, finally market and social needs depend with each others to fulfill their needs. Political changes also made by this Korean soap opera. Because of whole society change by the opera and political some 
characters changed like Changumi from their vision and used Changumi's characteristic ideology for growing up their political campaigns. At the highest influence of this drama. Sri lankan president also made his speech with the examples giving examples from Changumi soap opera.

Religious monks also attached examples from the Changumi story when they giving speech for the people as a social influence and change in the society. Especially historical connections Sri lanka and Korea improved after telecasted that tv series from Sri lanka rupavahini cooperation. It may be a big rapport building of influence from such soap opera series.

As a conclusion can be said there is a big imagine and ideology, physiological, philosophical impact has occurred to the Sri lankan audience. It came from the after telecasted Changumi soap opera tv series. Whole the society changed with the impact of this tele series. It sometimes became a lunacy for the Sri lankan society and good and bad effects partly. At last we can see this tv series made a sequence impact for the Sri lankan whole society.

\section{REFERENCES}

[1] Brooks, P (1995). The Melodramatic Imagination: Melodrama, and the Mode of Excess. Yale University Press.

[2] Browns. Bo, (2006), A Jewel of power and brilliance Korean drama: Dae Jang Geum/Jewel in the palace, spring issue.

[3] Buwalda. Hans, (2004 February) Testing and analysis, Soap opera testing, Best software, www.stickyminds.com.

[4] Lee.K.W and Hahn I.T,(2013) The Characteristic of Korean soap opera: It's focus on the structure of family power relation with Interrelationship, International journal of Multimedia and ubiquitous Engineering, vol 8, no5, pp 259264.

[5] Schemering, C, (1985. September), The Soap opera encyclopedia, pp 66-73, ISBN 0-345-32459-5.

[6] Soap opera, Collins English Dictionary- Complete and unabridged (10th ed.), Harper Collins publishers, July 2013. 